\title{
Linkage isomerism in 4-(2-aminoethyl)morpholine (L) complexes of nickel (II) nitrite: X-ray single crystal structure of trans-[ $\left[\mathrm{NiL}_{2}\left(\mathrm{NO}_{2}\right)_{2}\right]$
}

\author{
Tanmay Chattopadhyay ${ }^{\mathrm{a}}$, Manami Ghosh ${ }^{\mathrm{a}}$, Adinath Majee ${ }^{\mathrm{a}}$, \\ Munirathinam Nethaji ${ }^{*, b}$, Debasis Das ${ }^{\mathrm{a}, *}$ \\ a Department of Chemistry, Visva-Bharati University, Siksha-Bhavana, Santiniketan 731 235, India \\ ${ }^{\mathrm{b}}$ Department of Inorganic and Physical Chemistry, Indian Institute of Science, Bangalore 560 012, India
}

\begin{abstract}
The linkage isomers trans-bis[4-(2-aminoethyl)morpholine]dinitronickel (II) (brown, 1a) and trans-bis[4-(2-aminoethyl)morpholine]dinitritonickel (II) (blue-violet, 1b) have been synthesized from solution. Complex 1a is the major and thermodynamically controlled product, whereas, complex $\mathbf{1 b}$ is minor and kinetically controlled product. The X-ray single crystal structure analysis of complex 1a has been performed.
\end{abstract}

Keywords: Linkage isomerism; 4-(2-Aminoethyl)morpholine; Nickel (II) nitrite

\section{Introduction}

Jorgensen first rationalized the ambidentate behavior of the nitrite ion as early as 1894 [1]. Since then several interesting reports of nitrite coordination have come in the literature, which reveal that there are nine different ways in which the nitrite ion may coordinate as a ligand (Scheme 1). These different modes of binding generate linkage isomerism in nitrite complexes. The most well know systems are the monodentate nitro and nitrito linkage isomers obtained with cobalt (III), nickel (II), copper (II), rhodium (III) and platinum (IV). The nitro-nitrito linkage isomerism in nickel (II) amine systems have been investigated by several groups of workers [2-11]. It has been suggested that a steric effect favors the binding of the nitrite ion through oxygen to yield the nitrito isomer, although they are thermodynamically unstable. In order to study the influences of steric and electronic factors on

\footnotetext{
${ }^{*}$ Corresponding author. Tel.: +9103324837031; fax: +9103463252 672.

E-mail address: dasdebasis2001@yahoo.com (D. Das).
}

the mode of nitrite coordination in the nickel (II) system, the co-ligands that seem to be best suited are 1,2-diaminoethane and its derivatives, as different substituents may be tailored on the backbone of 1,2-diaminoethane to obtain the desired steric and electronic effects. For $\mathrm{NiL}_{2}\left(\mathrm{NO}_{2}\right)_{2}$, when $\mathrm{L}=N, N^{\prime}$-dimethyl-1,2-diaminoethane only the trans-dinitro species can be isolated in the solid state as well as in solution [9], when $\mathrm{L}=$ $N, N^{\prime}$-diethyl-1,2-diaminoethane a nitrito $(\mathrm{O}, \mathrm{O})$ complex is obtained in the solid state which exhibits a nitro-nitrito $(\mathrm{O}, \mathrm{O})$ equilibrium in different solvents, though the nitro form cannot be isolated in the solid state [6a], and when $\mathrm{L}=N, N^{\prime}$-dipropyl-1,2-diaminoethane a metastable (at ca. $298 \mathrm{~K}$ ) trans-dinitro species is formed which gradually transforms into the nitrito $(\mathrm{O}, \mathrm{O})$ species, and that trans-dinitro form may be preserved by keeping the species below $283 \mathrm{~K}$ [11d]. To date only one report of monodentate nitro and nitrito linkage isomers of nitrite complexes of nickel (II) has been cited in the literature, with $\mathrm{L}=1-(2$-aminoethyl)piperidine [11a]. The steric and electronic factors are just perfectly balanced in this case to generate the monodentate nitro as well 
(i)<smiles>[M]C(O)O</smiles>

(iv)<smiles></smiles>
nitrito $(\mathrm{O}, \mathrm{O})$

(vii)<smiles>[M]ONO[M]</smiles>

(ii)<smiles>[M]O[14CH][14CH2]O</smiles>

(v)<smiles>[M]ON([M])O[AlH]</smiles>

(viii)

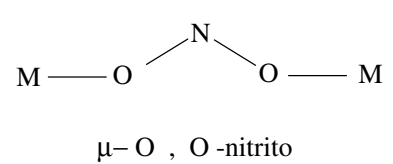

(iii)

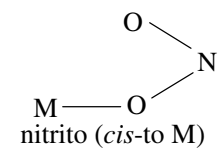

(vi)<smiles>[M]O[N+]([M])[O-]</smiles>

(ix)<smiles>[M]ON(OC)O[Al]</smiles>

Scheme 1. Nine possible modes of nitrite ion coordination to metal.

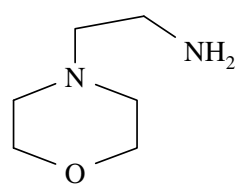

4 - (2- aminoethyl)morpholine

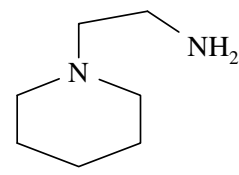

1- (2-aminoethyl)piperidine
Scheme 2. Molecular structures of the ligands.

as the monodentate nitrito linkage isomers in the solid state. Therefore, the steric and electronic factors of the co-ligand may impart interesting findings in nitrite coordination. For the present study we have chosen 4-(2-aminoethyl)morpholine (Scheme 2) as the co-ligand, which should exert nearly equal steric and electronic effects in comparison with 1-(2-aminoethyl)piperidine (Scheme 2), with the view to obtain some interesting results. We report herein the synthesis and characterization of nitro and nitrito complexes of nickel (II) of 4-(2-aminoethyl)morpholine and the X-ray single crystal structure analysis of the nitro species.

\section{Experimental}

\subsection{Materials}

4-(2-Aminoethyl)morpholine was purchased from Aldrich Chemical Company Inc. and used as received. Potassium hexanitronickelate (II) monohydrate was prepared using a standard method [6b]. All other chemicals used were of AR grade.

\subsection{Physical measurements}

Elemental analyses (carbon, hydrogen and nitrogen) were performed using a Perkin-Elmer 240C elemental analyzer; the nickel (II) content was estimated gravimetrically [12]. The IR spectrum $\left(4000-400 \mathrm{~cm}^{-1}\right)$ was taken at $27^{\circ} \mathrm{C}$ using a SHIMADZU FTIR-8400S and $\mathrm{KBr}$ was used as the medium. The electronic spectrum (1400-200 nm) was obtained at $27^{\circ} \mathrm{C}$ using a SHIMADZU UV-3101PC, and Nujol was used as a medium as well as a reference. The magnetic susceptibility was measured at $27^{\circ} \mathrm{C}$ using an EG and G PAR 155 vibrating sample magnetometer, and $\mathrm{Hg}\left[\mathrm{Co}(\mathrm{SCN})_{4}\right]$ was used as a reference material; diamagnetic corrections were made using Pascal's constants [13]. Molar conductances were measured using a Systronic 304 conductivity meter, where the cell constant was calibrated with $0.02 \mathrm{M} \mathrm{KCl}$ solution and dry dichloromethane was used as the solvent.

\subsection{Synthesis of the complexes}

The nitro $\left[\mathrm{NiL}_{2}\left(\mathrm{NO}_{2}\right)_{2}\right]$ (1a) and nitrito $\left[\mathrm{NiL}_{2}-\right.$ $\left.(\mathrm{ONO})_{2}\right](\mathbf{1 b})$ complexes were synthesized by adding the ligand $\mathrm{L}(2 \mathrm{mmol})$ in methanol $(5 \mathrm{~mL})$ dropwise to a methanolic suspension $(10 \mathrm{~mL})$ of potassium hexanitronickelate (II) monohydrate $(1 \mathrm{mmol})$ with vigorous stirring. Initially a clear green solution was formed, but within a few minutes a blue-violet precipitate also appeared. After $1 \mathrm{~h}$ of stirring the mixture was filtered and the green colored filtrate part was kept in a $\mathrm{CaCl}_{2}$ desiccator. After a few days, brown-colored crystals (1a) separated out from the green solution. Yield 65\%. Anal. Calc. for $\mathrm{C}_{12} \mathrm{H}_{28} \mathrm{~N}_{6} \mathrm{O}_{6} \mathrm{Ni}$ : C, 38.0; H, 7.4; N, 22.2; Ni, 15.5. Found: C, 38.0; H, 7.3; N, 22.1; $\mathrm{Ni}, \quad 15.6 \% . \quad \mu_{\text {eff }}=3.2 \mu_{\mathrm{M}} . \quad \lambda_{\max }(\mathrm{Nujol})=1264,1182$, $535,371 \mathrm{~nm}$. The blue-violet precipitate part was dissolved in excess methanol, and the resulting green colored solution was kept in a $\mathrm{CaCl}_{2}$ desiccator. After a few days a blue-violet species was deposited at the sidewalls of the beaker and brown crystals were formed at the bottom of the beaker. After crystallization of the blue-violet species, complex $\mathbf{1 b}$ was isolated in pure form. Yield: $25 \%$. Anal. Calc. for $\mathrm{C}_{12} \mathrm{H}_{28} \mathrm{~N}_{6} \mathrm{O}_{6} \mathrm{Ni}$ : C, 38.0; H, 7.4; N, 22.2; Ni, 15.5\%. Found: C, 38.1; H, 7.3; N, 22.0; Ni, 15.4\%. $\mu_{\mathrm{eff}}=3.2 \mu_{\mathrm{M}} . \lambda_{\max }(\mathrm{Nujol})=$ 1255, 1192, 588, $412 \mathrm{~nm}$. 


\subsection{X-ray data collection and structure determination}

A single crystal suitable for X-ray data collection was mounted on Bruker SMART CCD diffractometer equipped with a graphite monochromated Mo $\mathrm{K} \alpha$ $(\lambda=0.71073 \AA)$ radiation source. The program SMART [14] was used for collecting frames of data, indexing reflection and determination of lattice parameters, SAINT [14] for integration of the intensity of reflections and scaling, and SADABS [15] for absorption correction. A total 2977 reflections were measured and 2366 were assumed observed applying the condition $I>2 \sigma(I)$. The structure was solved by direct methods using the SHELXs-97 [16] computer program and refined by full-matrix least squares methods on $F^{2}$, using the SHELXL-97 [17] program with anisotropic displacement parameters for all non-hydrogen atoms. Selected crystallographic data and refinement details are displayed in Table 1. Selected bond lengths and angles are given in Table 2.

\section{Results and discussion}

When a methanolic solution of $\mathrm{L}$ was added to a methanolic suspension of potassium hexanitronickelate (II) monohydrate, a blue-violet precipitate was formed within a few minutes, during the stirring. On filtration a green colored solution was obtained which on keeping yielded complex 1a. After repeated crystallization of the

Table 1

Crystal data and structure refinement of complex 1a

\begin{tabular}{|c|c|}
\hline Empirical formula & $\mathrm{C}_{12} \mathrm{H}_{28} \mathrm{~N}_{6} \mathrm{NiO}_{6}$ \\
\hline Formula weight & 411.09 \\
\hline$T(\mathrm{~K})$ & 293 \\
\hline Mo K $\alpha$ & 0.71073 \\
\hline Crystal system & triclinic \\
\hline Space group & $P 1$ \\
\hline$a(\AA)$ & $7.1761(16)$ \\
\hline$b(\AA)$ & $8.0904(18)$ \\
\hline$c(\AA)$ & $8.3814(19)$ \\
\hline$\alpha\left({ }^{\circ}\right)$ & $94.116(3)$ \\
\hline$\beta\left(^{\circ}\right)$ & $112.337(2)$ \\
\hline$\gamma\left({ }^{\circ}\right)$ & $101.296(3)$ \\
\hline$V\left(\AA^{3}\right)$ & $435.60(17)$ \\
\hline$Z$ & 1 \\
\hline$D_{\text {calc }}\left(\mathrm{Mg} \mathrm{m}^{-3}\right)$ & 1.567 \\
\hline$F(000)$ & 218 \\
\hline$\mu\left(\mathrm{mm}^{-1}\right)$ & 1.2 \\
\hline$\theta$ Range $\left(^{\circ}\right)$ & $2.6-28.4$ \\
\hline Reflection collected & 2977 \\
\hline Independent reflection & 2420 \\
\hline Reflection observed & $2366[I>2 \sigma(I)]$ \\
\hline Goodness of-fit on $F^{2}$ & 1.07 \\
\hline$R_{\text {int }}$ & 0.013 \\
\hline$R$ & 0.0273 \\
\hline$w R$ & 0.0698 \\
\hline
\end{tabular}

Table 2

Selected bond lengths $(\AA)$ and bond angles $\left({ }^{\circ}\right)$ of complex 1a

\begin{tabular}{lr}
\hline Ni1-N1 & $2.069(3)$ \\
Ni1-N2 & $2.336(3)$ \\
Ni1-N3 & $2.032(4)$ \\
Ni1-N4 & $2.372(3)$ \\
Ni1-N5 & $2.135(3)$ \\
Ni1-N6 & $2.101(4)$ \\
O1-N5 & $1.197(5)$ \\
O2-N5 & $1.218(5)$ \\
O3-N6 & $1.276(6)$ \\
O4-N6 & $1.258(5)$ \\
N1-Ni1-N2 & $80.23(12)$ \\
N1-Ni1-N3 & $177.72(14)$ \\
N1-Ni1-N4 & $99.00(13)$ \\
N1-Ni1-N5 & $89.71(13)$ \\
N1-Ni1-N6 & $90.07(15)$ \\
N2-Ni1-N3 & $97.50(12)$ \\
N2-Ni1-N4 & $179.20(13)$ \\
N2-Ni1-N5 & $93.48(12)$ \\
N2-Ni1-N6 & $87.79(14)$ \\
N3-Ni1-N4 & $83.28(13)$ \\
N3-Ni1-N5 & $90.32(14)$ \\
N3-Ni1-N6 & $89.95(15)$ \\
N4-Ni1-N5 & $86.70(13)$ \\
N4-Ni1-N6 & $92.02(14)$ \\
N5-Ni1-N6 & $178.65(15)$ \\
O3-N6-O4 & $114.1(4)$ \\
O1-N5-O2 & $120.3(4)$ \\
\hline
\end{tabular}

blue-violet species, complex $\mathbf{1 b}$ was obtained in the pure form. Complex 1a was the major and thermodynamically controlled product, whereas complex $\mathbf{1 b}$ was the minor and kinetically controlled product. The composition of the complexes 1a (brown) and 1b (blue-violet) have been assigned as $\mathrm{NiL}_{2}\left(\mathrm{NO}_{2}\right)_{2}$ on the basis of elemental analyses. Magnetic susceptibility measurements of $1 \mathbf{a}$ and $\mathbf{1 b}$ reveal that nickel (II) is in an octahedral configuration in both complexes and electronic spectral data of the complexes suggest that they have octahedral geometry around the nickel (II) centre. IR spectral studies are observed to be immensely helpful to elucidate the binding mode of the nitrite ion in its complexes. The three fundamental vibrational modes of the nitrite group ( $C_{2 v}$ symmetry) are all IR active and the band positions are shifted upon coordination. The brown species 1a exhibits IR bands at 1333, 1310 and $808 \mathrm{~cm}^{-1}$ assigned to $v_{\mathrm{as}}\left(\mathrm{NO}_{2}\right), v_{\mathrm{s}}\left(\mathrm{NO}_{2}\right)$ and $\delta\left(\mathrm{NO}_{2}\right)$, respectively. Both $v_{\text {as }}\left(\mathrm{NO}_{2}\right)$ and $v_{\mathrm{s}}\left(\mathrm{NO}_{2}\right)$ are shifted to higher frequencies as compared to the free nitrite ion (1329 and $1264 \mathrm{~cm}^{-1}$ ) suggesting that the nitrite ion is coordinated via the $\mathrm{N}$ atom [2,11a]. The blue-violet species $\mathbf{1 b}$ shows two sets of bands for $v_{\text {as }}\left(\mathrm{NO}_{2}\right)\left(1365\right.$ and $\left.1331 \mathrm{~cm}^{-1}\right)$ and $v_{\mathrm{s}}\left(\mathrm{NO}_{2}\right)\left(1318\right.$ and $\left.1304 \mathrm{~cm}^{-1}\right)$ in its IR spectrum. The complex $\mathbf{1 b}$ may be either the monodentate nitrito species or the nitrito $(\mathrm{O}, \mathrm{O})$ species. Generally, nitrito species exhibit $v_{\text {as }}\left(\mathrm{NO}_{2}\right)$ at a higher frequency (observed for $\mathbf{1 b}$ ) and $v_{\mathrm{s}}\left(\mathrm{NO}_{2}\right)$ at a lower frequency (not observed for $\mathbf{1 b})$ than the free nitrite ion frequencies [11a,18]. On the other hand, nitrito $(\mathrm{O}, \mathrm{O})$ species show a lowering of 
both $v_{\mathrm{as}}\left(\mathrm{NO}_{2}\right)$ and $v_{\mathrm{s}}\left(\mathrm{NO}_{2}\right)$ in comparison to free ion frequencies. Therefore, from the IR spectrum of $\mathbf{1 b}$ it is difficult to assign the coordination mode of the nitrite ion in it. Now the electronic spectral and electrolytic conductance studies may impart some light on the mode of nitrite ion coordination especially in $\mathbf{1 b}$. Electronic spectral data indicate that both $\mathbf{1 a}$ and $\mathbf{1 b}$ possess octahedral geometry around nickel (II) and since they exhibit further splitting in the $\mathrm{d}-\mathrm{d}$ band in the near-IR region they should have a trans-configuration [19]. The electrolytic conductance measurements in dichloromethane suggest that both $\mathbf{1 a}$ and $\mathbf{1 b}$ are non-conducting $\left(\Lambda_{\mathrm{m}}=7.1\right.$ and $4.3 \Omega^{-1} \mathrm{~cm}^{2} \mathrm{~mol}^{-1}$ for $\mathbf{1 a}$ and $\mathbf{1 b}$, respectively). Since $\mathbf{1 b}$ shows non-electrolytic behavior in noncoordinating solvents like dichloromethane it should be a nitrito species not the nitrito $(\mathrm{O}, \mathrm{O})$ species. From the above results it may be assumed that both $\mathbf{1 a}$ and $\mathbf{1 b}$ possess a trans-octahedral geometry, and $\mathbf{1 a}$ and $\mathbf{1 b}$ are, respectively, the nitro and nitrito linkage isomers.

The ORTEP view of complex 1a with the atom numbering scheme has been depicted in Fig. 1. The selected bond lengths and bond angles are shown in Table 2. The hydrogen bonding is presented in Table 3 . The structure consists of a discrete $\mathrm{NiL}_{2}\left(\mathrm{NO}_{2}\right)_{2}$ molecule and the nickel atom occupies an inversion center. The coordination polyhedron around the metal atom may be best described as a distorted octahedron. The four nitrogen atoms of the diamine part of the ligands $(\mathrm{N} 1, \mathrm{~N} 2$ and their centrosymmetrically related atoms) define the equatorial plane and the two nitrogen atoms belonging to the nitro groups (N5 and its centrosymmetric counter part) coordinate in trans axial positions. The $\mathrm{Ni}-\mathrm{N}$ (amine) distances, ranging between 2.032(4) and 2.372(3) $\AA$, are consistence with the corresponding values observed in similar systems. The discrepancy between the two $\mathrm{Ni}-\mathrm{N}$ distances is a consequence of the steric constraints imposed by the bulky morpholine

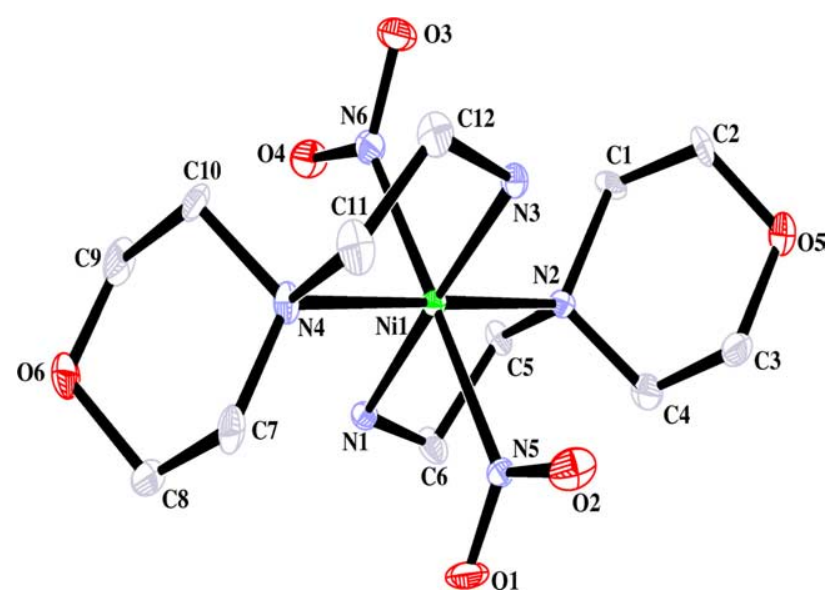

Fig. 1. ORTEP [21] diagram of trans-[ $\left[\mathrm{NiL}_{2}\left(\mathrm{NO}_{2}\right)_{2}\right](\mathbf{1 a})[\mathrm{L}=4-(2-$ aminoethyl)morpholine] with the atom numbering scheme. Ellipsoids are drawn at $50 \%$ probability.
Table 3

H-bonding list for complex 1a

\begin{tabular}{|c|c|c|c|c|}
\hline $\mathrm{D}-\mathrm{H} \cdots \mathrm{A}$ & $\mathrm{D}-\mathrm{H}$ & $\mathrm{H} \cdots \mathrm{A}$ & $\mathrm{D} \cdots \mathrm{A}$ & $\angle \mathrm{D}-\mathrm{H} \cdots$ \\
\hline $\mathrm{N} 1-\mathrm{H} 1 \mathrm{~A} \cdots \mathrm{O} 1^{\mathrm{a}}$ & 0.9001 & 2.4179 & $2.869(5)$ & 111.22 \\
\hline $\mathrm{N} 1-\mathrm{H} 1 \mathrm{~A} \cdots \mathrm{O}^{\mathrm{a}}$ & 0.9001 & 2.2971 & $3.008(6)$ & 135.77 \\
\hline $\mathrm{N} 1-\mathrm{H} 1 \mathrm{~B} \cdots \mathrm{O} 4^{\mathrm{b}}$ & 0.9002 & 2.4179 & $2.979(5)$ & 120.67 \\
\hline $\mathrm{N} 1-\mathrm{H} 1 \mathrm{~B} \cdots \mathrm{O} 5^{\mathrm{b}}$ & 0.9002 & 2.3680 & $3.164(5)$ & 147.41 \\
\hline $\mathrm{N} 3-\mathrm{H} 3 \mathrm{~A} \cdots \mathrm{O} 2^{\mathrm{c}}$ & 0.8998 & 2.4347 & $2.973(5)$ & 118.63 \\
\hline $\mathrm{N} 3-\mathrm{H} 3 \mathrm{~A} \cdots \mathrm{O}^{\mathrm{c}}$ & 0.8998 & 2.4024 & $3.187(5)$ & 145.74 \\
\hline $\mathrm{N} 3-\mathrm{H} 3 \mathrm{~B} \cdots \mathrm{O}^{\mathrm{d}}$ & 0.9005 & 2.3904 & $3.085(6)$ & 134.05 \\
\hline $\mathrm{N} 3-\mathrm{H} 3 \mathrm{~B} \cdots \mathrm{O} 3^{\mathrm{d}}$ & 0.9005 & 2.4847 & $2.952(6)$ & 112.73 \\
\hline $\mathrm{C} 3-\mathrm{H} 3 \mathrm{D} \cdots \mathrm{O} 3^{\mathrm{e}}$ & 0.9700 & 2.4708 & $3.398(6)$ & 159.89 \\
\hline $\mathrm{C} 4-\mathrm{H} 4 \mathrm{~B} \cdots \mathrm{N} 5^{\mathrm{e}}$ & 0.9709 & 2.6131 & $3.198(6)$ & 118.94 \\
\hline $\mathrm{C} 5-\mathrm{H} 5 \mathrm{~B} \cdots \mathrm{O} 4^{\mathrm{e}}$ & 0.9705 & 2.5920 & $3.330(5)$ & 132.94 \\
\hline C9-H9A $\cdots$ O1 $^{\mathrm{f}}$ & 0.9700 & 2.5503 & $3.503(6)$ & 167.43 \\
\hline $\mathrm{C} 10-\mathrm{H} 10 \mathrm{~A} \cdots \mathrm{N} 6^{\mathrm{f}}$ & 0.9693 & 2.5664 & $3.155(7)$ & 119.22 \\
\hline
\end{tabular}

${ }^{a}$ Symmetry codes: $1+x, y, z$.

b Symmetry codes: $x, y,-1+z$.

${ }^{c}$ Symmetry codes: $x, y, 1+z$.

d Symmetry codes: $-1+x, y, z$.

e Symmetry codes: $1+x, y, 1+z$

${ }^{\mathrm{f}}$ Symmetry codes: $-1+x, y,-1+z$.

group. The crystal packing diagram of $\mathbf{1 a}$, done by using program PLATON99 [20], is shown in Fig. 2 which reveals a two dimensional infinite chain structure through a hydrogen bonding network.

The proposition made regarding the structure of complex 1a and the coordination mode of the nitrite ions in it by routine physicochemical techniques have been established unambiguously through the X-ray single crystal structure analysis of 1a. Our efforts to synthesize single crystals of $\mathbf{1 b}$ yielded no results. However, routine physicochemical studies suggest that $\mathbf{1 b}$ should be a monodentate nitrito species with a trans-octahedral

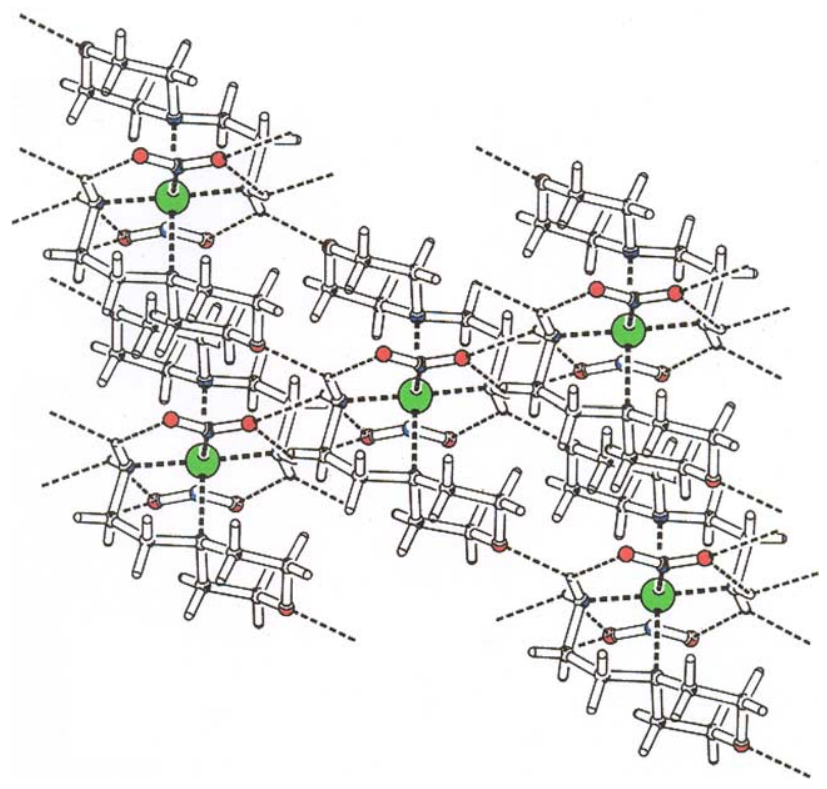

Fig. 2. Crystal packing diagram of trans- $\left[\mathrm{NiL}_{2}\left(\mathrm{NO}_{2}\right)_{2}\right](\mathbf{1 a})[\mathrm{L}=4-(2-$ aminoethyl)morpholine] and H-bonds (-----) in the crystal structure. 
configuration. Therefore, the bulkiness of the morpholine moiety in the ligand 4-(2-aminoethyl)morpholine is just the optimum to stabilize both the nitro and nitrito isomers in the solid state as we observed earlier only in one case with the ligand 1-(2-aminoethyl)piperidine.

\section{Acknowledgments}

The authors thank the Council of Scientific and Industrial Research, New Delhi (Grant to D.D. \& A.M; Project No. 01(1871)/03/EMR-II dated 17/03/ 2003) for financial support. We (D.D. \& A.M.) also thank the Department of Science and Technology (DST), New Delhi for providing FTIR and UV-VISNIR spectrophotometers and the networking facility through the DST-FIST program.

\section{Appendix A. Supplementary data}

Supplementary data are available from the Cambridge Crystallographic Data Centre, 12, Union Road, Cambridge CB2 1EZ, UK (fax: +44-1223-336033; e-mail: deposit@ccdc.cam.ac.uk) on request, quoting the deposition number CCDC 264274. Supplementary data associated with this article can be found, in the online version, at doi:10.1016/j.poly.2005.04.039.

\section{References}

[1] S.M. Jorgensen, Z. Anorg. Chem. 5 (1894) 168.

[2] K. Nakamoto, J. Fujita, H. Murta, J. Am. Chem. Soc. 80 (1958) 4817.

[3] M.G.B. Drew, D.M.L. Goodgame, M.A. Hitchman, D. Rogers, Proc. Chem. Soc. (1964) 363.

[4] M.A. Porai-koshits, L.K. Minacheva, J. Struc. Chem. (Engl. Transl.) 5 (1964) 595.

[5] (a) D.M.L. Goodgame, M.A. Hitchman, Inorg. Chem. 3 (1964) 1389; (b) D.M.L. Goodgame, M.A. Hitchman, Inorg. Chem. 4 (1965) 721 ;

(c) D.M.L. Goodgame, M.A. Hitchman, Inorg. Chem. 6 (1966) 1303.

[6] (a) R.W. Green, J. Chem. Soc., Chem. Commun. (1969) 1463; (b) R.W. Green, B. Bell, Aust. J. Chem. 26 (1973) 1663.

[7] A.E. Shvelashvili, L.P. Sarishvili, R.M. Vashaidze, Russ.J. Inorg. Chem. 19 (1974) 307.

[8] M.J. Goldberg, R.E. Marsh, Acta Crystallogr., Sect. B 35 (1979) 960.

[9] A.J. Finney, M.A. Hitchman, C.L. Raston, G.L. Rowbottom, A.H. White, Aust. J. Chem. 34 (1981) 2047, 2069, 2085, 2125, 2141 and 2163.

[10] M.A. Hitchman, G.L. Rowbottom, Coord. Chem. Rev. 42 (1982) 55.

[11] (a) D. Das, I.R. Laskar, A. Ghosh, A. Mondal, K. Okamoto, N. Ray Chaudhuri, J. Chem. Soc., Dalton Trans. (1998) 3979;

(b) I.R. Laskar, G. Mostafa, D. Das, K. Okamoto, N. Ray Chaudhuri, Acta Cryst. C55 (1999) 1994;

(c) I.R. Laskar, A. Ghosh, G. Mostafa, D. Das, A. Mondal, N. Ray Chaudhuri, Polyhedron 19 (2000) 1015;

(d) I.R. Laskar, D. Das, G. Mostafa, T.H. Lu, T.C. Keng, J.C. Wang, A. Ghosh, N. Ray Chaudhuri, New J. Chem. 25 (2001) 764.

[12] A.I. Vogel, A Text Book of Quantitative Inorganic Analysis, fourth ed., Longman, New York, 1978.

[13] B.N. Figgis, J. Lewis, in: J. Lewis, R.C. Wilkins (Eds.), Modern Coordination Chemistry, fourth ed., Interscience, New York, 1960, p. 403.

[14] SMART and SAINT Software Reference Manuals, Version 6.22, Bruker AXS Analytic X-Ray Systems, Inc., Madison, WI, 2000.

[15] G.M. Sheldrick, SADABS, Software for Empirical Absorption Correction, University of Gottingen, Germany, 2000.

[16] G.M. Sheldrick, SHELXs-97, Program for Solution of Crystal Structure, University of Gottingen, Germany, 1997.

[17] G.M. Sheldrick, SHELXL-97, Program for Solution of Crystal Structure, University of Gottingen, Germany, 1997.

[18] K. Nakamoto, Infrared Spectra of Inorganic and Coodination Compounds, Wiley, New York, 1977, p. 223.

[19] A.B.P. Lever, Inorganic Electronic Spectroscopy, second ed., Elsevier, Amsterdam, 1984, p. 507.

[20] A.L. Spek, Platon, Molecular Geometry Program, University of Utrecht, The Netherlands, 1999.

[21] C.K. Johnson, ORTEP, III Report ORNL - 5138, Oak Ridge National Laboratory, Oak Ridge, TN, USA. 